\title{
CIÊNCIA DE FORMA LÚDICA E INTERATIVA
}

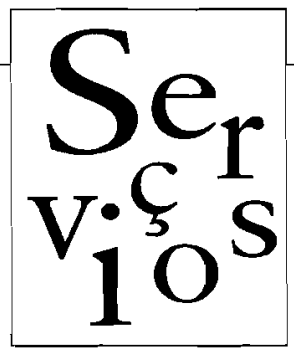

A Estação Ciência, centro de difusão científica, tecnológica e cultural da Universidade de São Paulo, em convênio com o Conselho Nacional de Desenvolvimento Científico e Tecnológico (CNPq), está completando 12 anos. Inaugurada em 1987, a "Estação" como é carinhosamente chamada pelos funcionários e muitos freqüentadores - oferece à população, principalmente alunos e professores da rede escolar, a oportunidade de conhecer, entender e analisar fenômenos, conceitos, teorias e algumas pesquisas científicas desenvolvidas nos diversos departamentos da USP. Trata-se, na verdade, de uma vitrina da Universidade e de outras instituições ligadas à produção, divulgação e ensino das ciências.

Instalada no prédio de uma antiga tecelagem construída na década de 30 , hoje em processo de tombamento pelo Conselho de Defesa do Patrimônio Histórico, Arqueológico, Artístico e Turístico do Estado de São Paulo (Condephaat), a Estação Ciência possui uma área total de $5.328 \mathrm{~m}^{2}$, dos quais $3.619 \mathrm{~m}^{2}$ são ocupados por exposições permanentes e temporárias, além de aparelhos e experimentos práticos de física, química, biologia, geologia, história e outras áreas do conhecimento. Atualmente é coordenada por Ernst W. Hamburger, professor titular do Instituto de Física (IFUSP).

Sua área expositiva foi organizada a partir da divisão do espaço em três plataformas: Ciência, Tecnologia e Informática. A Plataforma Ciência é constituída por painéis sobre astronomia, aparelhos para medições meteorológicas, um atlas e um globo terrestre gigantes, jogos de lógica e matemática, maquetes de um vulcão e dobras geológicas e o painel de "Aves Urbanas", com imagens e cantos de pássaros, entre outras coisas. Mas os destaques são as Cortinas do Tempo - que permitem uma divertida viagem pelo tempo através de diversas imagens da Praça da Sé, Lapa e Parque Dom Pedro (bairros da cidade de São Paulo) em diferentes épocas históricas - e os apareIhos que reproduzem diversos fenômenos físicos, como o modelo de uma usina hidrelétrica, o Gerador de Van der Graff - máquina capaz de carregar eletrostaticamente com uma carga positiva os corpos que estão ao seu redor, arrepiando os cabelos dos visitantes e mostrando diferentes princípios da Física - e o Betraton, primeiro acelerador de partículas do Brasil, montado em 1953 pelo professor Marcelo Damy de Souza Santos.

A Plataforma Ciência apresenta, ainda, no andar superior, a Parada Butantan, uma exposição de animais vivos e material demonstrativo sobre répteis e anfibios, mantida por meio da colaboração do Museu do Instituto Butantan.

$\mathrm{Na}$ Plataforma Tecnologia, a exposição "Do Poço ao Posto", organizada pela Petrobrás, mostra o processo de perfuração, extração e produção de petróleo, assim como seu refino, transporte e comercialização, retratados a partir de painéis fotográficos, maquetes, vídeos e computadores. Além disso, o público encontra um carro em corte lateral (fornecido pela GM do Brasil), o que possibilita o
A AUTORA
André Chaves de Melo Süva
Jomalista, historiador e professor. $\mathrm{E}$ assessor de imprensa da Estação Ciências USP. 
contato com os processos de fabricação da indústria automobilística, um modelo de satélite desenvolvido pelo Instituto de Pesquisas Espaciais (INPE) e fotos tiradas de satélites de várias regiões brasileiras, cedidas pelo professor Aziz Ab'Saber.

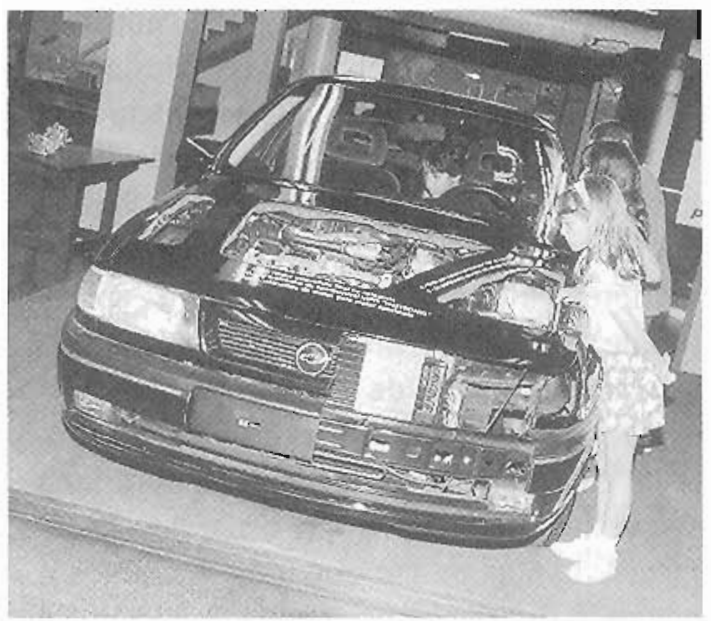

Crianças conhecem a estrutura interna de um automóvel exposto na Estaçāo Ciência.

Os destaques desta plataforma são: a coleção de biologia marinha, com 70 espécies de animais expostos em vidros e conservados em formol; o aquário de água salgada, povoado por caranguejos-ermitão, aranhas, estrelas, pepinos e ouriços-do-mar, anêmonas, baiacus, peixes cardeal, uma lagosia e um polvo, que encantam adultos e crianças; 0 aquário de água doce, no qual residem peixes da Amazônia, o que permite a observação do ecossistema dos rios dessa região.

A Plalaforma Informática é composta por painéis que retratam a evolução da informática até os dias de hoje e alguns microcomputadores doados pela Olivetti, Microtec e Intel, que podem ser manipulados pelo público sob a orientação de monitores - que são estudantes universitários treinados para atender os visitantes -, o que permite uma visita mais lúdica e interativa.
Quem não está com tempo para visìtar a Estação Ciência pode conferir tudo o que ela oferece por meio da sua página na Internet http://www.eciencia.usp.br. Ela foi eleita, este ano, Pagina Nota 10 pela EscolaNet, site criado para orientar professores, alunos e o público em geral através da seleção, classificação e divulgação das páginas brasileiras da Internet que trazem contribuições para a educação e a divulga ção do conhecimento.

Criada pela Site Net S/C Ltda e patrocinada pelas empresas Microlec, Auge e Vitech America, a EscolaNet (hup://www. escolanet.com.br) avalia as páginas por meio de cinco critérios: estar em porluguês, conteúdo cultural e educativo nos artigos e textos, apresentação visual, resolução das imagens e objetivos não-comerciais. Para serem selecionadas e receberem o selo Página Nota 10, as homepages precisam ser aprovadas em todos os quesilos.

\section{PREAMIOS DA ESTACÃO CIÊNCIA}

A partir da parceria da Olivetti com a Estação Ciência e a Universidade Federal de Santa Catarina (UFSC), foi desenvolvido por Nélson Canzian da Silva e Lucas Meyer o programa educativo "Oficina de Funções", que ficou em primeiro lugar no Concurso Nacional de Software para Instítuições de Ensino Superior 1997, promovido pelo Ministério da Educação e do Desporto. O concurso foi criado para divulgar, no âmbito das instituições de ensino superior nacionais, a produção de softwares voltada para uma perspectiva de estudo e pesquisa no país. E estimular, ainda, o desenvolvimento de programas educacionais para o ensino de primeiro e segundo graus. 
Requisitado por escolas de todo o Brasil, "Oficina de Funções" facilita o ensino da Matemática e da Física. Através de uma interface muito simples, calcula e apresenta o gráfico de algumas funções. $O$ usuário escolhe os coeficientes de diversas funçōes, que o programa desenha em frações de segundos. O software contém um texto detalhado (help), com explicações, exemplos e desafios. Entretanto, a utilizaçăo do programa facilita o aprendizado, mas não elimina a necessidade de elaborar gráficos manualmente, o que é essencial para seu uso eficaz.

A série de dez vinhetas "Minuto Científico" é outra iniciativa da "Estação" que teve seu valor enquanto instrumento educativo, reconhecido através de diversos prêmios. O último deles foi o de melhor projeto de difusão científica para a juventude do $9^{\circ}$ Festival Téléscience, realizado em Montreal, Canadá, em novembro de 1998. Idealizadas por Ernst W. Hamburger, as vinhetas do "Minuto" despertam a curiosidade do lelespectadol para grandes questões da ciência. Dirigido por Cao Hamburger, o "Minuto Científico" foi produzido pela TV Cultura e Esiação Ciência, com o apoio do Ministério da Cultura.

\section{EXPOSIÇÕES ITINERANTES}

Após permanecerem por alguns meses na Estação Ciência, muitos de seus projetos podem ser vistos em outros espaços, como bibliotecas, fundações, institutos, escolas e centros culturais, por meio das Exposições Itinerantes. São mostras curiosas sobre diversos temas que podem ilustrar e enriquecer as programações culturais e didáticas. Entre elas, destacam-se:

Uma História da Física Nuclear: registra o desenvolvimento dessa ciência em 31 países, mostrando a evolução do modelo de áromo, com as descobertas do elétron, da radioatividade e do modelo atômico. Aborda ainda a energia atômica e os raios cósmicos.

Em Tarno de Zumbi - Navio Negreiro cotidiano, castigo e rebelião escrava: é um projeto cuidadoso formado por painéis fotográficos com textos que retratam como era a vida diária da população escrava no Brasill, suas formas de insurreição, a luta pela identidade e as relações raciais atuais.

O Brasil de Portinari: formada por 50 réplicas digitais das principais obras do mestre Cândido Portinari, a mostra, patrocinada
A coleçāo biologia marinha da Estação Ciẻncia reserva surpresas emocionantes às crianças.

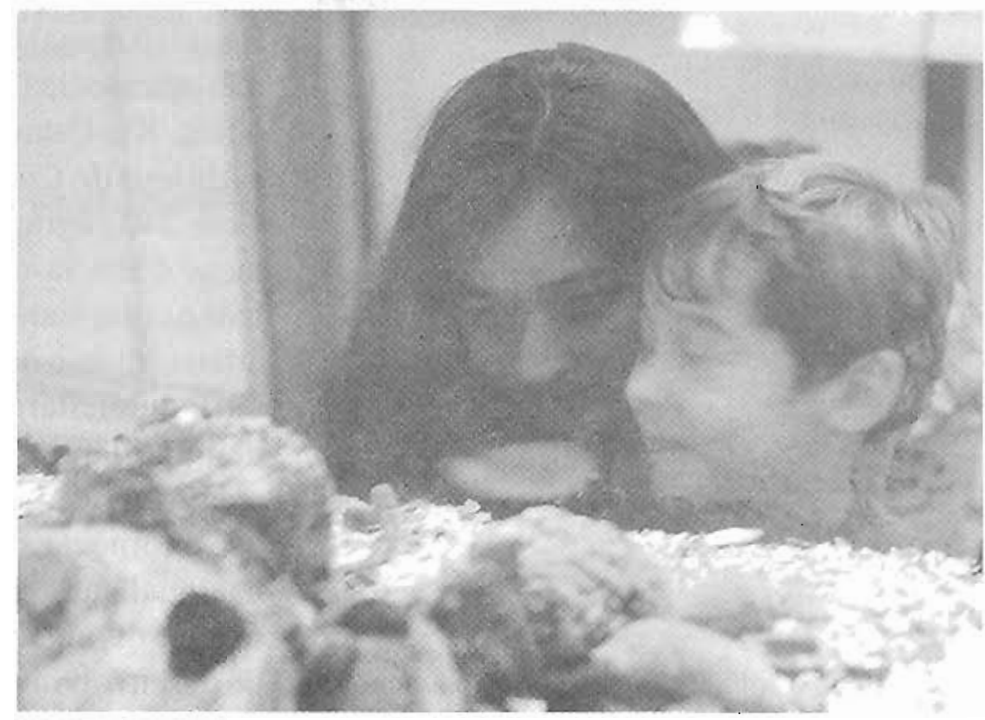


pela Petrobrás, faz parte do Projeto Portinari, que nasceu para resgatar e apresentar a obra do artista ao grande público. As reproduções permitem que o público entre em contato com a visño do pintor sobre a diversidade cultural e racial do país.

São Paulo e oulras cidades - Produção Social e Degradação dos Espaços Urbanos: mostra técnicas de construção civil e apresenta marcos da arquitetura da cidade de São Paulo, valorizando a memória do nosso patrimônio arquiterônico e relacionando as mudanças na paisagem com o processo de industrialização da cidade. Também aborda aspectos das cidades de Santos, Guarujá e Sorncaba.

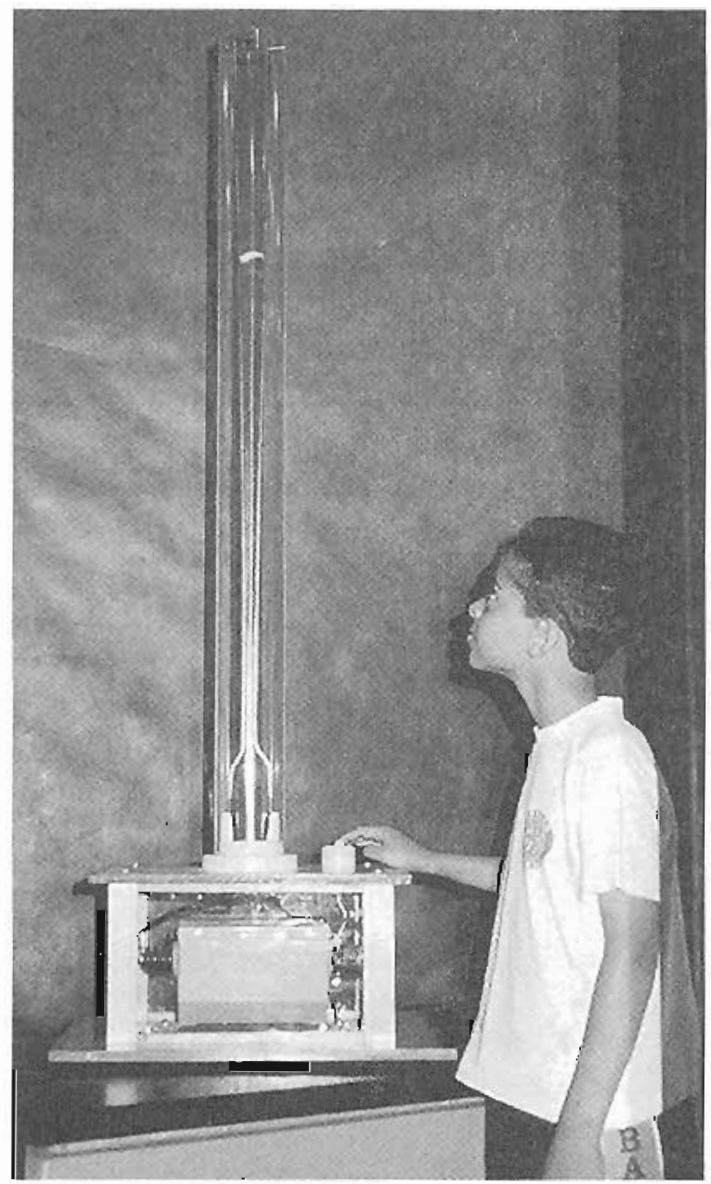

Experimentos científicos encantam as crianças.
Os Cinqüenta Anos do Méson p: homenagem ao físico César Lates, descobcidor da partícula subnuclear Méson p, retrata o início das pesquisas científicas nacionais e a importância que teve a descoberta de Lates para a criação do Conselho Nacional de Desenvolvimento Científico e Tecnológico (CNPq).

Ritmos da vida - Cronobiologia: apresenta os conceitos da Cronobiologia, ciência que estuda os ritmos físiológicos e comportamentais dos seres vivos.

\section{QUALIOADE DE ENSINO E DIVERSÃO}

Outra iniciativa é o Projeto Clicar, que se caracteriza por ser um trabalho inovador que a Estação Ciência está desenvolvendo desde 1996 e conta, atualmente, com o patrocínio da Petrobrás. Através da informática está estimulando a aprendizagem e o conbecimento de crianças e adolescentes, em siluação de rua, pela tecnologia e outras formas de aprendizado. Até o momento, cerca de 446 jovens foram atendidos pelo projeto, que recentemente recebeu a doação de mais doze microcomputadores da Microtec e Intel. o que ampliou sua capacidade de atendimento.

Em 1998 foi lançado, durante a $50^{\mathrm{a}}$ Reunião Anual da Sociedade Brasileira para o Progresso da Ciência (SBPC), realizada em Natal, Rio Grande do Norte, o livro Centros e Museus de Ciência. Visões e Experiências. Com 240 páginas, a obra, publicada pela Esração Ciência e Editora Saraiva, reúne trabalhos originais de 37 renomados cientistas, artistas (como o cantor e compositor Gilberto Gil), publicitários, autoridades e lideranças de importantes centros de ciência do Brasil e da América Latina. O objelivo da publicação é folnecer subsídios para uma discussão nacional sobre a inserção de museus e centros de divulgação científica nas estratégias de desenvolvimento científico e tecnológico. 
Com o tema $O$ Desafio de Ensinar Ciências no Século XXI, a Estação Ciência promoveu, entre os dias 18 e 22 de agosto, a $4^{a}$ Mostra de Material de Divulgação e Ensino das Ciências. Evento anual, tem por objetivo estimular professores, estudantes universitários e do ensino básico (fundamental e médio), pesquisadores, construtores e empresas a criar e difundir materiais que possam ser utilizados como instrumentos complementares no processo educativo.

O evento foi montado a partir de estandes com tamanho entre 4 e $24 \mathrm{~m}^{2}$, onde os participantes apresentaram para o público seus projetos, experimentos, resultados de pesquisas e pro-

Resumo: A Estação Ciência é um centro de difusão científica, tecnológica e cultural da Universidade de São Paulo, inaugurada em 1987, com sede no bairro da Lapa, em São Paulo. Dirigida a estudantes de todos os niveis de escolaridade e aos interessados em Ciência. Abriga exposições permanentes e temporárias, aparelhos e experimentos práticos de física, química, biologia, geologia, história, além de outras áreas do conhecimento. Seu espaço físico está dividido em três grandes plataformas temáticas: Ciência, Tecnologia e Informática. Produziu a série Minuto Científico - vinhetas de cunho educativo - que obteve, em 1998, o prêmio do Festival Téléscience, no Canadá. Desenvolve, ainda, o Projeto Clicar, que através da informática estimula o aprendizado de jovens em situação de rua.

Palavras-chave: Estação Ciência, difusão científica, Ciência, informática, tecnologia dutos. Durante a exposição foram realizadas as seguintes atividades paralelas: simpósio Difusão Científica, Educação e Sociedade, oficinas, palestras, demonstrações do funcionamento de alguns materiais e a entrega dos prêmios da segunda edição do concurso da mostra, destinado a professores do ensino fundamental e médio. Para o ano 2000, a Estação Ciência provavelmente irá realizar a $5^{a}$ edição da mostra, além de outros projetos, incluindo a conclusão da reforma de suas instalações, iniciada este ano. Aguardem.

A Estação Ciência fica na rua Guaicurus, 1.274 - Lapa - São Paulo - CEP 05033-002 Fone: (01 1) 263-7022 - Fax (011) 263-2798.

Abstract: Estação Ciência (Science Station) is a center for scientific, technological and cultural divulging belonging to the University of São Paulo, that was inaugurated in 1987, and has headquarters in the Lapa district, in São Paulo. It is aimed at students at all schooling levels and also at all those interested in Science. It houses permanent and temporary exhibitions, devices and practical experiments in physics, chemistry, biology, geology, history, over and beyond other knowledge areas. Its physical space is divided into three major thematic platforms: Science, Technology, and Computer Science. It produced the Minuto Científico (Scientific Minute) serieseducational vignettes - that was awarded, in 1998, with the Téléscience Festival prize, in Canada. It also produces the Projeto Clicar (Click Project), that stimulates street kids to learn using computer science.

Key words: Estação Ciência, scientific broadcast, Science, computer science, technology 